\title{
Olaf Leonhardt wird Geschäftsbereichsleiter
}

O

laf Leonhardt hat zum 1. April die

Leitung des Geschäftsbereichs

Fahrzeugindustrie mit globaler Verantwortung bei der SCA Schucker GmbH \& Co. KG in Bretten übernommen.

Leonhardt ist seit fast 20 Jahren bei SCA tätig, hat sieben Jahre lang die Forschung und Entwicklung geleitet und umfangreiches Anwendungs-Knowhow speziell bezüglich der Fertigungsprozesse in der Automobilindustrie gesammelt. Diese Erfahrung will er nun als Geschäftsbereichsleiter in den Vertrieb einbringen. „Heute werden weltweit über 70 Millionen Pkw pro Jahr produziert, in drei bis fünf Jahren werden es über 90 Millionen Autos sein“, sagt Leonhardt. „Und das Wachstum wird hauptsächlich in Asien generiert.“ Er sehe daher die Etablierung eines globalen Key-Account-Managements als seine vorrangige Aufgabe, um eine wachstumsfähige Organisation aufzubauen und neue Kunden vor allem in China und Japan anzusprechen.

$\mathrm{Zu}$ den von SCA umgesetzten Anwendungen im Automobilbau zählen hauptsächlich Stütz- und Festigkeitsverklebungen, Abdichtungen und spritzbare Dämmungsmassen für den Karosseriebau und Lackierstraßen, aber auch Dichtungslösungen für den Motorenund Getriebebau oder das Verkleben von Scheiben und Cockpitelementen.

Olaf Leonhardt übernahm bei SCA in Bretten zum 1. April die Leitung des Geschäftsbereichs Fahrzeugindustrie.

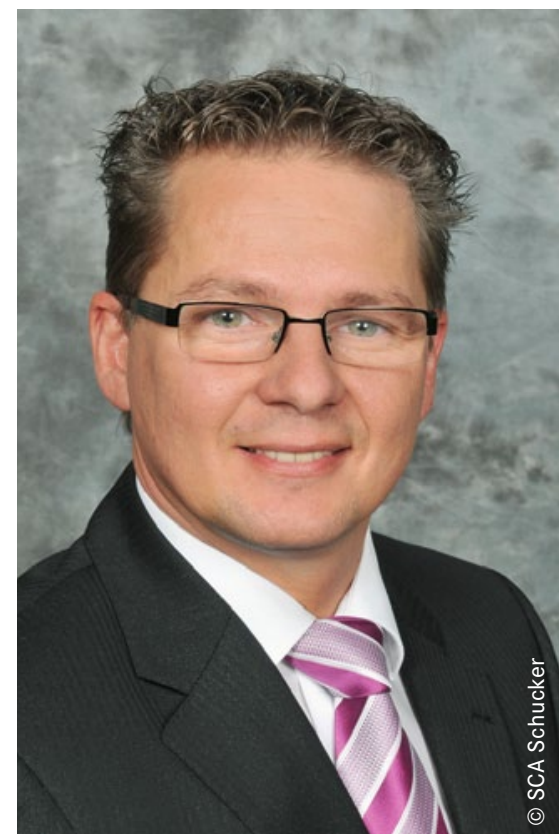

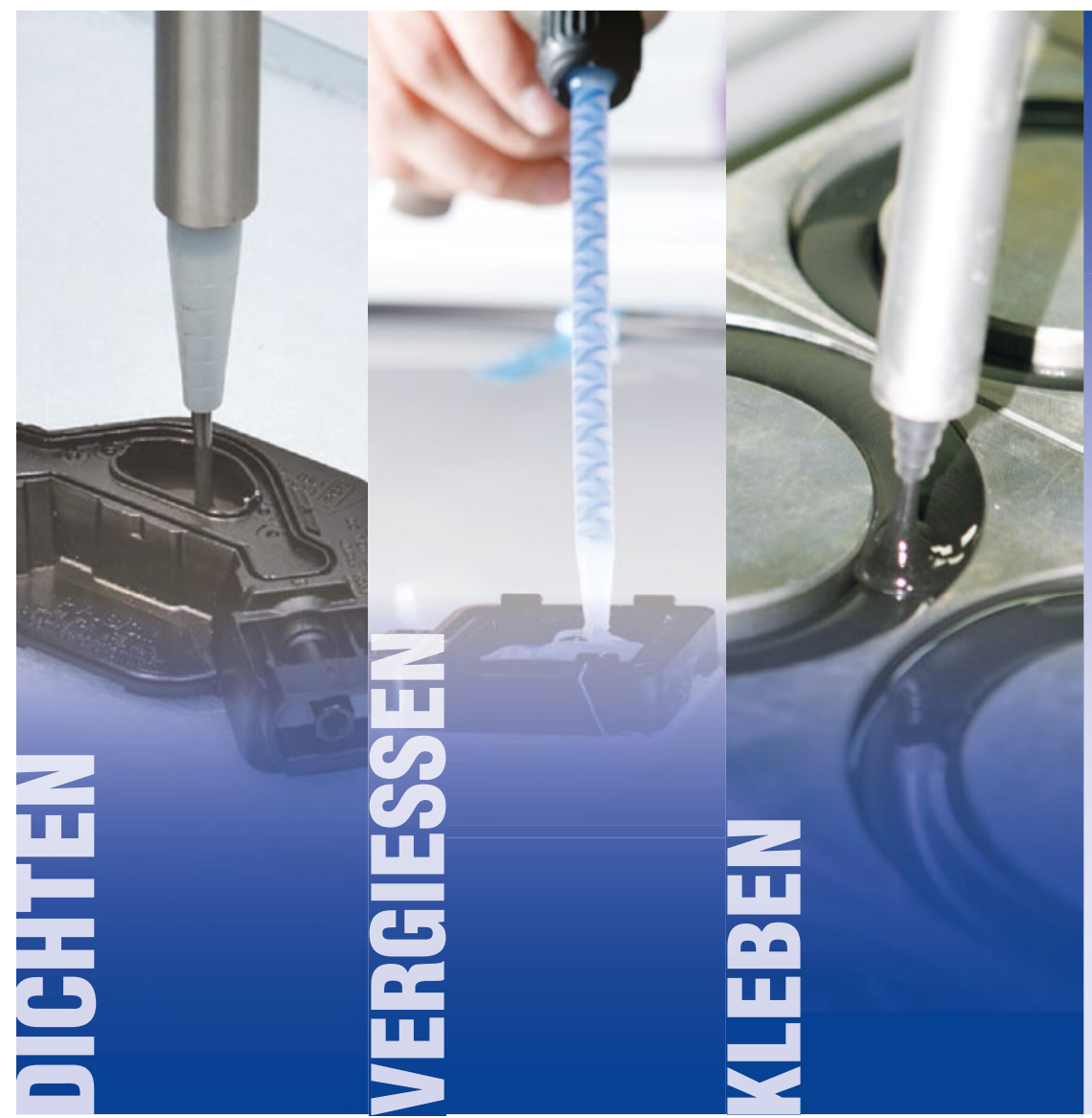
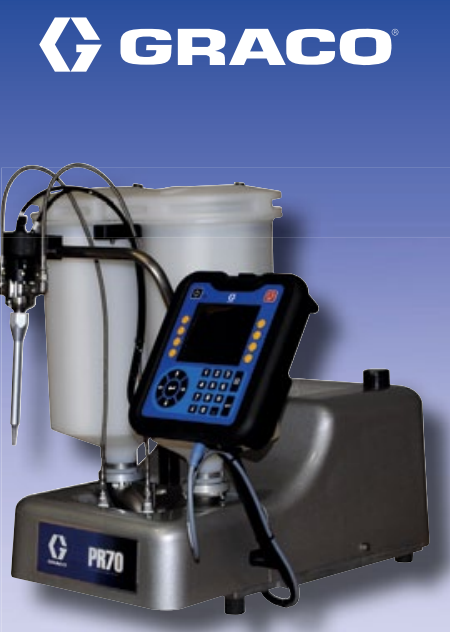

PR70'TM

Dosier-, Misch- und Austragssystem für Zweikomponenten-Materialien sowie Epoxy Dichtmaterialien, Kleber, Silicone und Utherane und mehr...

Machen Sie Ihr Leben ein Stück einfacher mit der PR70. Nehmen Sie mit uns Kontakt auf: pr70.33.graco.eu.com

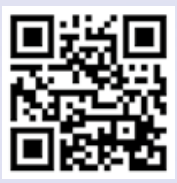

